\title{
Capacitação para o aperfeiçoamento do conhecimento tecnológico aos alunos do Ensino Médio
}

\author{
Yuri L. S. F. Magalhães ${ }^{1,2}$, Italo H.S.Silva ${ }^{1,2}$, Cassiano H. de Albuquerque ${ }^{1,2}$ \\ ${ }^{1}$ Instituto Federal de Educação, Ciência e Tecnologia do Sertão Pernambucano - \\ Campus Floresta \\ ${ }^{2}$ GITEC - Grupo de Pesquisa em Inovações Tecnológicas na Gestão de Hardware, \\ Software e Peopleware \\ yuhferraz@hotmail.com, herbertitalo@hotmail.com, \\ cassiano.henriquedifsertao-pe.edu.br
}

\begin{abstract}
Pernambuco promote the "Aluno Conectado" Program since 2012, which consists the distribution of hybrid computers to the students from high school in the state network, aiming to foment the digital inclusion. In this sense, researchers from "Instituto Federal do Sertão Pernambucano" is making an analysis of the efficiency of the program performing a study of the case in outback of Pernambuco. As a result, is a proposal a methodology of complementary training for assist the success of the "Aluno Conectado" Program.
\end{abstract}

Resumo: Pernambuco promove, desde 2012, o Programa Aluno Conectado, que consiste na distribuição de computadores híbridos aos alunos do ensino médio da rede estadual de ensino com a finalidade de promover a inclusão digital. Neste contexto, pesquisadores do Instituto Federal do Sertão Pernambucano realizam uma análise da eficácia do Programa realizando um estudo de caso no sertão de Pernambuco. Como resultado, é proposta uma metodologia de capacitação complementar para auxiliar o êxito do Programa Aluno Conectado. 


\section{Introdução}

As tecnologias da informação evoluem e integram cada vez mais os processos de ensino e aprendizagem nos ambientes de ensino. $\mathrm{O}$ volume de informação criado no mundo cresce exponencialmente.

A temática da inclusão digital permeia as variadas matérias do relacionamento humano e da vida em sociedade, estando intrinsecamente inserida nos processos econômicos do capitalismo. Pois, o acesso à Rede Mundial de Computadores e aos equipamentos de tecnologia, bem como o conhecimento referente a estes tópicos, são indissociáveis da integração social moderna, dos exercícios de cidadania e da atuação do homem no mercado financeiro em geral.

De acordo com NETO (2013) "Pernambuco inova e distribui Tablets para estudantes da rede estadual. O programa Aluno Conectado foi, dessa forma, anunciado pelo governo pernambucano e segundo dados do site oficial do estado, até setembro do mesmo ano foram distribuídos 156 mil tablets nas 1.101 escolas do sistema estadual de ensino. Esse ano devem ser distribuída por volta de metade desse número, aproximadamente, mais 80 mil. Os gastos com os equipamentos do primeiro ano do projeto, segundo o site, chegaram a 98 milhões." De acordo com a Secretária de Educação e Esportes de Pernambuco (2014). Este programa entregou em torno de 370 mil tablets entre os anos de 2012 e 2014.

Segundo Cafezeiro (2006) "Muitos dos alunos do Pré-Universitário não possuem nenhum conhecimento em informática, e não têm meios de acesso a computador." E na maioria do caso, são alunos que tem baixa renda e não têm acesso a inclusão digital.

Para Zanela, Brito (2005) "A utilização da tecnologia na educação como uma metodologia estimuladora da aprendizagem, assim como os computadores ligados em rede estão mudando a natureza do ensino e do aprendizado."

Neste contexto, a rede estadual de ensino público pernambucano, especificamente o ensino médio regular, pode utilizar a ferramenta distribuída pelo Programa Aluno Conectado de tal modo que alinhem-se os objetivos pedagógicos às estratégias de ensino propostas pelo MEC, a saber, por exemplo: ensino médio comprometido com a diversidade socioeconômica e cultural da população brasileira; e integração e articulação entre ensino médio e educação profissional. Considerando ainda que, "segundo o INEP o Brasil investiu em $2011 \mathrm{R} \$ 12.637,00$ por aluno durante o ensino médio, de um total de $\mathrm{R} \$ 142.261,00$ ao longo dos 18 anos dos diferentes níveis acadêmicos do ensino básico ao superior" (Sá et al, 2014).

No entanto, ao contatar os alunos contemplados pelo programa visitando os mesmos nas próprias escolas, foram muitos e recorrentes os relatos de problemas decorridos do mal uso do Tablet/PC do "Aluno Conectado". Alguns estudantes relataram que as máquinas estavam com softwares "piratas" ou que as máquinas estavam repletas de vírus de computador. Pode-se observar que por falta de conhecimento sobre informática básica os alunos excluíam software importantes para o funcionamento da máquina, tais como antivírus, softwares de escritório, o software agente de segurança que serve para inibir o roubo ou furto da máquina. Observou-se que os estudantes não registravam e nem atualizavam os softwares dos computadores o que 
acarretava vários problemas que acabavam por diminuir drasticamente o desempenho da máquina.

Essa pesquisa beneficia alunos do ensino médio das escolas estaduais da Zona Rural da Região de Itaparica situada no sertão do estado de Pernambuco, que inclui os seguintes municípios: Belém do São Francisco/PE, Carnaubeira da Penha/PE, Floresta/PE, Jatobá/PE, Petrolândia/PE, Tacaratu/PE e Itacuruba/PE, como mostra na Figura 1:

Figura 1. Mapa do Sertão de Itaparica- PE do Sub-Médio São Francisco (Citybrazil, 2015)

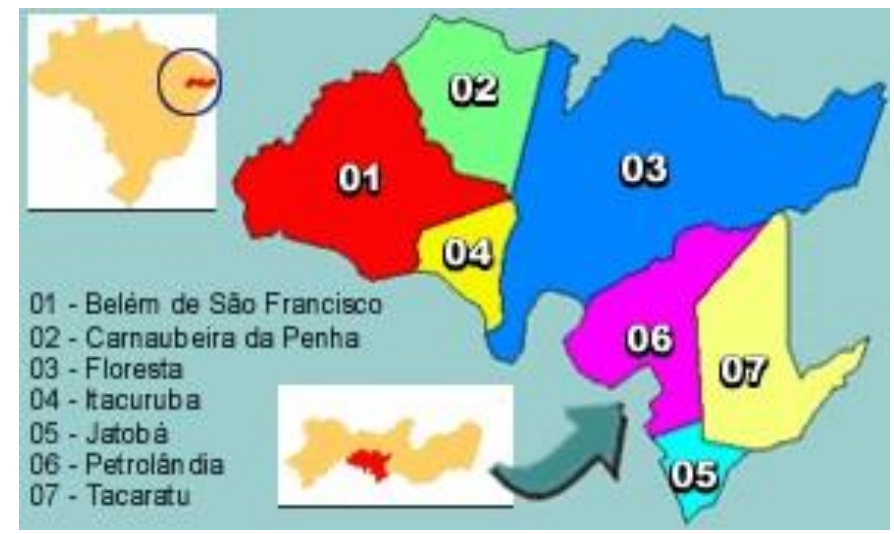

\section{Metodologia}

Desenvolvido entre junho de 2013 e maio de 2014, o projeto visava analisar a necessidade da capacitação complementar em informática básica para os alunos do ensino médio da Rede Estadual de Ensino da microrregião de Itaparica - PE, zona rural e urbana, contemplados pelo Programa Aluno Conectado. O projeto deu-se em 6 fases distintas, listadas a seguir:

1) Revisão bibliográfica: momento em que foi feito um levantamento e análise dos estudos existentes correlatos ao projeto, bem como do amparo legal do Programa Aluno Conectado.

2) Elaboração de material para treinamentos: num segundo momento o projeto direcionou-se para a elaboração de material didático - apresentação de slides - a ser utilizado na posterior capacitação.

3) Levantamento das Escolas contempladas: considerando que o escopo do projeto, delimitava sua atuação nas Escolas Estaduais da microrregião de Itaparica. Realizou-se um levantamento desse junto a Gerência Regional de Educação Sertão do Submédio São Francisco - Floresta.

4) Capacitação nas Escolas: entre outubro de 2013 e abril de 2014 foram visitadas 23 escolas, em 07 diferentes municípios, percorrendo aproximadamente 1000 quilômetros. Onde foram capacitados 1358 alunos, de 52 turmas distintas (conforme visto na Tabela 1).

5) Testes de Acompanhamento: junto a capacitação, eram aplicados questionários aos discentes para avaliar o nível de conhecimento em informática básica. $\mathrm{O}$ 
questionário, com 10 questões de múltipla escolha, foi aplicado a todas as 52 turmas.

6) Elaboração de Relatório Técnico de Conclusão: a fase final do projeto consistiu na elaboração de um relatório para documentar as informações inferidas através da pesquisa e da experiência vivenciada.

Tabela 1. Tabela que mostra todos os municípios e suas respectivas escolas que foram contempladas pelo Programa Aluno Conectado.

\begin{tabular}{|c|c|c|c|}
\hline Município & Quant. de Escola & Quant. de Alunos & Turmas \\
\hline Floresta-PE & 6 & 107 & 6 \\
\hline Itacuruba-PE & 1 & 111 & 3 \\
\hline $\begin{array}{c}\text { Belém do São } \\
\text { Francisco-PE }\end{array}$ & 5 & 443 & 14 \\
\hline Petrolândia-PE & 5 & 422 & 19 \\
\hline $\begin{array}{c}\text { Tacaratu-PE } \\
\text { Carnaubeira-PE }\end{array}$ & 2 & 134 & 5 \\
\hline Total & 2 & 141 & 5 \\
\hline
\end{tabular}

\section{Resultados}

Para promover a inclusão digital dos mesmos, não basta apenas entregar a ferramenta, pois de nada servirá a entrega sem que eles não tenham o entendimento de como realizar determinada função. Por isso, a importância da capacitação para que a inclusão desses discentes seja feita de maneira apropriada.

A ciência dessa necessidade motivou a realização da capacitação nas próprias instituições de ensino, para os estudantes do ensino médio contemplados pelo Programa, poderem incluir à tecnologia da informação na sua rotina, especialmente a escolar. Apesar da iniciativa louvável e bastante significativa do Governo do Estado de Pernambuco, esta pesquisa através da experiência de capacitação, evidenciou o quanto é ineficiente apenas disponibilizar a ferramenta tecnológica, no caso o Tablet/PC, do Programa Aluno Conectado.

Com base no que foi visto durante todo o tempo de capacitação, foi notório o quanto é preciso desta transmissão de conhecimento. Muitos desses alunos não faziam ideia do que estava sendo ministrado e, no final, com a aplicação de um questionário para saber o que foi absorvido pelos alunos, sempre tinha um rendimento baixo.

\section{Conclusão}

Esta pesquisa detectou a necessidade de se capacitar adequadamente os alunos do ensino médio da rede estadual de ensino, para que os mesmos usufruam plenamente 
da ferramenta para fins pedagógicos, bem como possam ter um conhecimento necessário para a utilização e conservação do bem recebido.

Foi detectada uma relativa discrepância em relação ao nível de conhecimento em tecnologia dos alunos da zona urbana, frente aos alunos da zona rural, onde por exemplo, os discentes não possuem nem mesmo acesso regular à internet na maioria dos casos. Mesmo assim, o número de problemas relatados pelos próprios estudantes, independentemente, de onde residam e estudem é comum e prejudica o aproveitamento da ferramenta entregue.

Conclui-se assim que, para o Programa Aluno Conectado atuar com eficácia fazse necessário instituir um cronograma regular de treinamento/capacitação em informática básica para os contemplados pelo programa. Tendo sido praticado numa escola de ensino médio da Rede Estadual de Pernambuco - Escola Três Marias em Floresta/PE - constatou-se que, o modelo de curso apresentado é satisfatoriamente operativo, já que muitos dos alunos que ganharam o tablet/PC não conheciam todos os softwares que vinham instalados, e só usavam os mesmos sem qualquer precaução. Assim, o modelo feito na Escola Três Marias, dando a capacitação de como melhor usar o tablet e suas ferramentas é de possível replicação em escolas ao longo do estado de Pernambuco. De acordo com o que foi visto na avaliação final, tendo mais de $60 \%$ dos alunos com nota abaixo da média.

Uma alternativa viável para o Governo do Estado seria adotar - com as adequações pertinentes - o modelo de curso aqui proposto, uma vez que o mesmo já foi planejado e executado com sucesso.

\section{Referências}

Cafezeiro, Isabel. EDUCAÇÃO, INFORMÁTICA E RESPONSABILIDADE SOCIAL: A CONTRIBUIÇÃO DA UNIVERSIDADE PÚBLICA. XVII Simpósio Brasileiro de Informática na Educação - SBIE - UNB/UCB - 2006. Brasília - DF. 2006.

CITYBRAZIL. Microrregião Itaparica. Disponível em: < http://www.citybrazil.com.br/pe/microregiao_detalhe.php?micro=6> Acesso em $10 \mathrm{de}$ Março de 2015.

NETO, Pedro Brandão da Costa. As tecnologias da informação e da comunicação e as políticas públicas de inclusão digital: distribuição de tablets em um estado do nordeste brasileiro. Ata Científica do XXIX Congreso de la Asociación Latinoamericana de Sociología, 2013. ISBN: 978-956-19-0828-4

SÁ, Yara R. P. S. M. de et al. TECNOLOGIA NA EDUCAÇÃO: Um Estudo de Caso do Programa Aluno Conectado na Microrregião de Itaparica no Sertão Pernambucano. IX Congresso de pesquisa e Inovação da Rede Norte e Nordeste de Educação Tecnológica. Maranhão. 2014.

Zanela, M.; Brito, G.S. A informática utilizada como ferramenta pedagógica: relato de experiência com a Base de Dados ASFA. XVI Simpósio Brasileiro de Informática na Educação - SBIE - UNB/UCB - 2005. Juíz de Fora - MG. 2005. 